isational structures. No attempt was made to do any type of structural analysis. Yet the reader is constantly reminded that 'these studies contribute greatly to our theory of community building'. Although community building is suggested as the theoretical contribution of these studies no use was made of any model or theory of community development. For example, the work of Herbert Gans on Levittowners, and the East London materials from Wilmott and Young, as well as the vast literature on planned communities is noticeably absent. It would appear that the author began with an assumption about age, not an assumption about community, and she ended with the same assumption.

In spite of these critical observations, the book does make a contribution. It adds additional descriptive information on retirement communities. Given the growing numbers of people in these age categories, one might suspect that there will be increasingly larger numbers of people living under similar arrangements in the future. There are enough data in this book to contribute to a theoretical statement about retirement communities; however, as the author demonstrates, there are not enough to construct a theory.

Virginia Commonwealth University,

ED K NIP E Richmond, Virginia, U.S.A.

\title{
Bernard Casey and Gerte Bruche, Work or Retirement? Labour Market and Social Policy for Older Workers in France, Britain, the Netherlands, Sweden and the U.S.A., Gower, 1983, 191 pp., £i3.50, ISBN o 566 oo6 89 .
}

This is an extremely valuable book, providing useful summaries of a range of policies affecting older workers in five countries - France, Great Britain, the Netherlands, Sweden and the U.S.A. The authors review measures for older workers still in employment, and policies aimed at assisting those experiencing long-term joblessness (in Britain, people aged $45+$ represent over half of the long-term unemployed).

The conclusions from this study, viewed through the eyes of older people themselves, are hardly reassuring. Adjusting workplaces in line with the needs of an ageing workforce is low in the priorities of most employers. Moreover, the supply of 'lighter work' has rapidly diminished in a climate of rationalisation of labour. Policies for reducing work-time have been more popular, either as a means of preparing the individual for retirement (Britain) or to reduce his or her workload in line with changing capacities (the Netherlands). Even here, however, only a minority of employers have developed such schemes.

Casey and Bruche examine various measures designed to protect the individual from dismissal. These include extensive state legislation (Sweden) or seniority rules and policies challenging age discrimination (U.S.A.). However, the authors make the important observation:

that a strategy of protection, whilst it might increase the job security of those who are 'in', might also intensify the re-entry problems of those who (e.g. as the result of a complete firm closure following a bankruptcy) are 'out' - this because the older workers' protected situation makes 
employers reluctant to hire them. Furthermore, strategies of protection are capable of being undermined by the co-existence of other policies which provide for substantial severance payments or generous levels of unemployment compensation to older workers, the latter often also in combination with the 'alternative role' of early pensioner (p.53).

The problems facing the elderly unemployed, when trying to get back into work, seem even more bleak. The reason for this, as the text makes clear, is that most countries give greater priority to the problem of youth unemployment. France and Britain make no particular provision to help those older people without work. The Netherlands and Sweden have made some attempts to expand job vacancies, but their policies have had only a modest effect. The American case is somewhat different. Due to an aggressive older persons' lobby, together with placement agencies and the provision for part-time work, a more positive view has emerged concerning the older person as employee. Even here, however, the jobs created are better described as forms of 'sheltered' employment, rather than genuine programmes of reintegration.

As these points would suggest, the main thrust of labour policy has been towards the exclusion of older people from work, with the provision of a variety of forms of income support to maintain the individual until the onset of state retirement age. The generosity of these schemes is subject to wide variation, with female early retirers and blue collar workers often experiencing lower rates of benefits (in comparison to those from white collar and managerial occupations).

As I remarked at the beginning of this review, this is an extremely useful book, representing a highly competent survey of a difficult area. In conclusion I would make just three observations. A major weakness of the text is that it fails to explore with sufficient clarity the differential impact of policies on male and female employees. Many of the policies discussed are targeted either explicitly or implicitly at male workers. As a consequence, for those interested in the labour problems experienced by older women workers, this book is of limited value. Secondly, although it may be difficult to envisage at this point in time, if labour shortages do reappear in western economies, then pressure on older people to remain at work is also likely to return. It is for this reason, perhaps, that labour policies are left somewhat flexible in the case of older people, with exclusion or retention being dominant themes. Finally, judging from the-somewhat brief discussion in the introduction, the authors have a rather simplistic approach to the vexed question of the productivity of older workers (suggesting that the vast majority of them are indeed 'less productive'). However, it is surely the case that the notion of productivity is socially constructed, pivoting around a range of social, cultural, economic and biological inputs. The text could have provided a more sustained discussion on the role played by these various elements and, correspondingly, their relative influence in the different countries studied.

Department of Adult Education, University of Keele

CHRIS PHILLIPSON 